\title{
Erratum to: Molecular dissection of placental malaria protein VAR2CSA interaction with a chemo-enzymatically synthesized chondroitin sulfate library
}

\author{
Nobuo Sugiura ${ }^{1}$ - Thomas Mandel Clausen ${ }^{2}$ Tatsumasa Shioiri ${ }^{1}$ - Tobias Gustavsson ${ }^{2}$. \\ Hideto Watanabe $^{1}$ - Ali Salanti ${ }^{2}$
}

Published online: 30 November 2016

(C) Springer Science+Business Media New York 2016

Erratum to: Glycoconjugate Journal

DOI 10.1007/s10719-016-9685-Z

The original version of this article unfortunately contained a mistake in the author group section. Tatsumasa Shioiri's name was incorrectly presented as "Tatsuasa Shioiri". The original article was corrected.

The authors apologize to readers for this error.

The online version of the original article can be found at http://dx.doi. org/10.1007/s10719-016-9685-Z

Nobuo Sugiura

nsugiura@aichi-med-u.ac.jp

$\triangle$ Thomas Mandel Clausen

tmc@sund.ku.dk

1 Institute for Molecular Science of Medicine, Aichi Medical

University, 1-1 Yazakokarimata, Nagakute, Aichi 480-1195, Japan

2 Centre for Medical Parasitology, Department of Immunology and

Microbiology, University of Copenhagen, CSS, Øster

Farigmagsgade 5A, 1014 Copenhagen K, DK, Denmark 